\title{
Beyond high school, 'colleges' teach medical marijuana
}

Amidst the remnants of the failing automobile industry in Michigan rises a new business: the production of medical marijuana.

Capitalizing on the fledgling but rapidly growing medical marijuana market is Med Grow Cannabis College, an institution that teaches cannabis growers the how-tos of cultivating the controversial plant. Located in Southfield, just outside of Detroit, the school was established in September last year-ten months after Michigan became the thirteenth US state to permit medical marijuana. Although less than a year old, the college has produced more than 1,000 graduates and is even attracting students from outside the state.

Although Med Grow is the only medical marijuana training center in Michigan, it is not the first in the nation. In 2007, Oaksterdam University started offering the first such courses in Oakland, California in the US.

Delta(9)-tetrahydrocannabinol (THC) is the main active ingredient of cannabis, but there are other active ingredients such as cannabidiol. The amount of these ingredients in cannabis can vary depending on both genetic composition and growing environment.

"Marijuana is not just marijuana," says Donald Abrams, professor of clinical medicine at the University of California-San Francisco and chief of oncology at San Francisco General Hospital. "The genetics of the plants dictate potency and the availability of other chemical that have medicinal properties." Abrams adds that, because cannabis is a plant, "as it is with any botanical medicine, it is difficult to standardize. Potency is different from a number of different factors-where it was grown, when it was harvested, the amount of light, water, etc."

Under Michigan law, patients who have been certified by their doctors as needing medical marijuana can grow up to 12 cannabis plants themselves or name a 'caregiver' who can grow the plant for them. Anyone over 21 years of age with a drug-free criminal record can be a caregiver for up to five patients.

About $70 \%$ of the students at Med Grow are, or would like to be, caregivers. The 30 -hour program can be taken over the course of six weeks for $\$ 475$ or be completed in an intensive five-day session for $\$ 595$. The curriculum covers a broad range of topics, including medical effects, legal issues and even cooking with cannabis. Horticulture classes are the backbone of the program. There are beginner and intermediate classes: beginner classes cover the basics of growth, flowering and harvesting, whereas intermediate classes address advanced techniques for breeding.

At the end of the program, students take a cumulative pen-and-paper examination to receive their certificates. "The certificates are not formally recognized by the government or medical practitioners, but increase a caregiver's credibility for patients who are looking for caregivers," says Nick Tennant, the 24-year-old founder of the school.

D Yvette Wohn, East Lansing, Michigan

\section{The state of clinical research in America}

The most populous three states in the US - California, Texas and New York - were the only states last year to launch more than 1,000 human clinical trials each. That's not surprising, given the millions of people inhabiting each of these states. But when you take into account the enormity of each region and look at the number of clinical trials per capita, the Golden, Lone Star and Empire States hardly register, and some surprising underdog states begin to stand out. Maybe Nebraska, the Cornhusker State, should be renamed the Clinical State.

New clinical trials initiated in 2009 by state

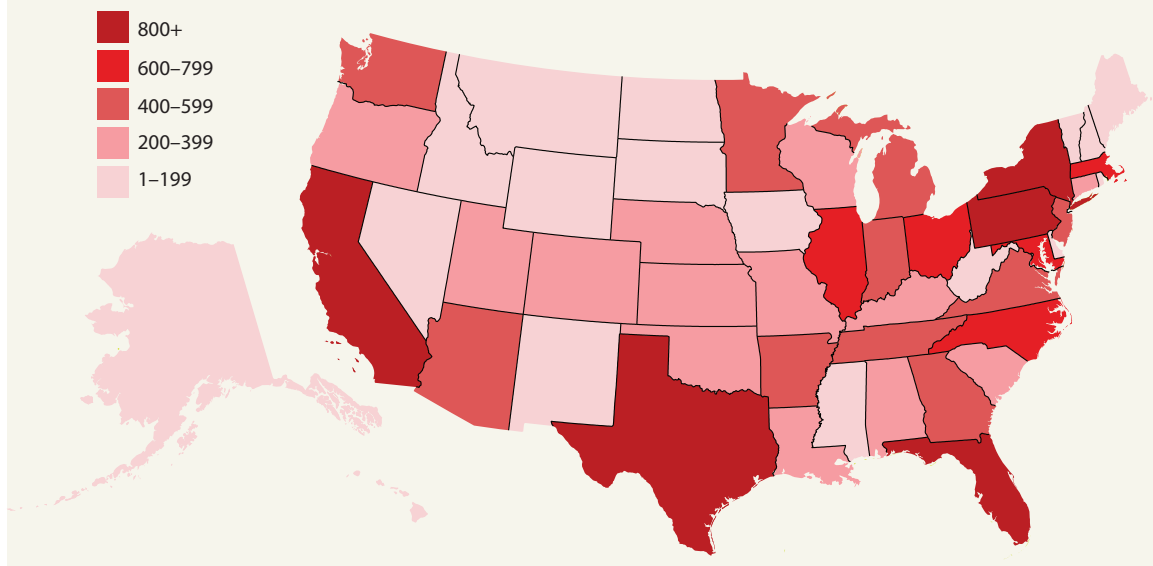

New clinical trials per one million people

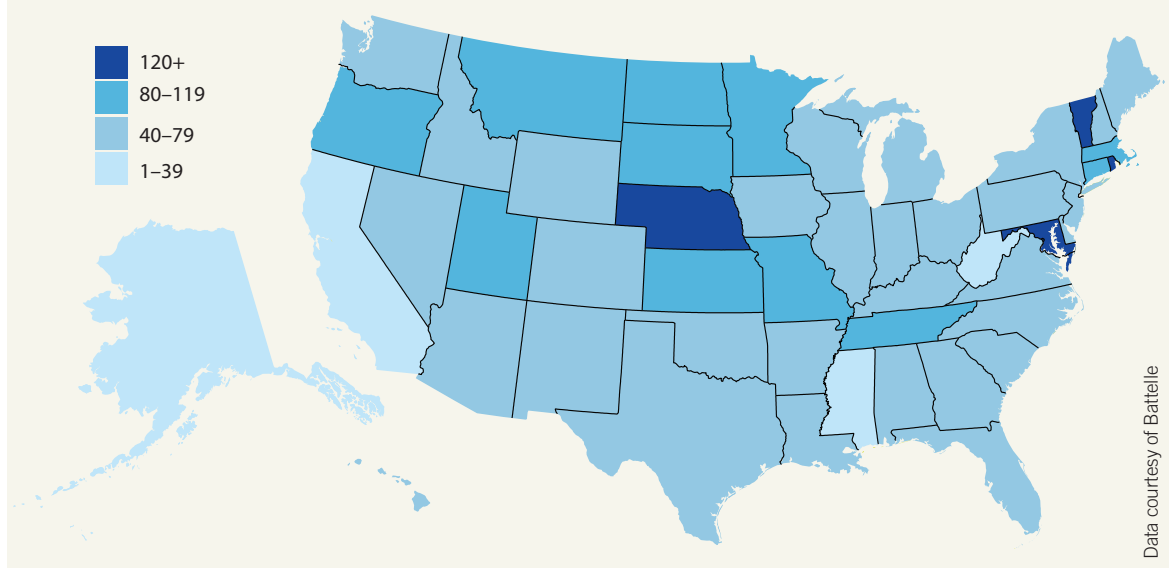

${ }^{a}$ Many clinical trials are run concurrently in multiple states, so adding up state totals will give a number larger than the US total. 